\title{
Effects of conjugated linoleic acid (CLA) isomers on lipid levels and peroxisome proliferation in the hamster
}

\author{
Emile A. M. de Deckere ${ }^{1}$, Johan M. M. van Amelsvoort ${ }^{1}$, Gerald P. McNeill ${ }^{2}$ and Penny Jones ${ }^{2}$ \\ ${ }^{1}$ Unilever Research Vlaardingen, PO Box 114, 3130 AC Vlaardingen, The Netherlands \\ ${ }^{2}$ Unilever Research Colworth, Sharnbrook, Bedford MK44 1LQ, UK
}

(Received 9 November 1998 - Revised 20 April 1999 - Accepted 13 May 1999)

\begin{abstract}
Effects of the conjugated linoleic acid (CLA) isomers cis-9, trans-11 (c9,t11 CLA) and trans-10, cis-12 (t10,c12 CLA) on lipid metabolism and markers of peroxisome proliferation were investigated in hamsters fed on purified diets containing $30 \%$ energy as fat and $0 \cdot 1 \mathrm{~g}$ cholesterol/kg for 8 weeks. Four groups (n 32 each) received diets without CLA (control), with a mixture of equal amounts of c9,t11 and t10,c12 CLA (CLA mix), with c9,t11 CLA, and with t10,c12 CLA. The total amount of CLA isomers was $1.5 \%$ energy or $6.6 \mathrm{~g} / \mathrm{kg}$ diet. CLA was incorporated into glycerides and exchanged for linoleic acid in the diet. Compared with the control, the CLA mix and t10,c12 CLA decreased fasting values of LDL- (21 and 18\% respectively) and HDL-cholesterol (8 and $11 \%$ ), increased VLDL-triacylglycerol (80 and $61 \%$ ), and decreased epididymal fat pad weights ( 9 and $16 \%$ ), whereas c9,t11 CLA had no significant effects. All CLA preparations increased liver weight, but not liver lipids. However, the increase in liver weight was much less in the c9,t11 CLA group ( $8 \%)$ than in the other two groups ( $25 \%$ ) and might have been caused by the small amount of t10,c12 CLA present in the c9,t11 CLA preparation. Liver histology revealed that increased weight was due to hypertrophy. Markers of peroxisome proliferation, such as cyanide-insensitive palmitoyl CoA oxidase (EC 1.3.3.6) and carnitine acetyl transferase (EC 2.3.1.7) activities, were not increased by CLA. Both c9,t11 CLA and t10,c12 CLA were incorporated into phospholipids and triacylglycerols, but t10,c12 CLA only about half as much as c9,t11 CLA. In addition, linoleic acid and linolenic acid concentrations were lower in lipids of the t10,c12 CLA group compared with the c9,t11 CLA group. These data suggest that t10,c12 CLA stimulated the oxidation of all $\mathrm{C}_{18}$ polyunsaturated fatty acids. The results indicate that the t10,c12 CLA isomer, and not the so-called natural CLA isomer (c9,t11), is the active isomer affecting lipid levels in hamsters.
\end{abstract}

Conjugated linoleic acid: Plasma lipids: Lipoproteins: Peroxisomes

Conjugated linoleic acid (CLA) refers to isomers of linoleic acid with several positional (positions 8 to 13) and geometric (cis, trans) conjugated double-bond configurations (Pariza, 1988). CLA is present in small amounts in dairy products and meat (Chin et al. 1992) and in partially hydrogenated vegetable oils and spreads made from such oils (Mossoba et al. 1991; Banni et al. 1994). It is even present in human milk and infant foods (McGuire et al. 1997). CLA is taken up and incorporated into triacylglycerols (TAG) and phospholipids (PL) (Britton et al. 1992; Huang et al. 1994; Banni et al. 1995). Beneficial effects of a mixture of CLA isomers (mainly cis-9, trans-11 CLA (c9, t11 CLA) and trans-10, cis-12 CLA (t10,c12 CLA)) have been found in a number of animal models of cholesterol metabolism and atherosclerosis (Lee et al. 1994; Nicolosi et al. 1997) and of carcinogenesis (Pariza, 1988; Ip et al. 1995; Visonneau et al. 1997). The studies on cholesterol metabolism are inconclusive and effects of the different isomers of CLA have not yet been studied. A process has been developed to separate the individual isomers of CLA and to incorporate them into glycerides, which has allowed us to study effects of c9,t11 CLA, t10,c12 CLA and a mixture of these isomers on lipid levels in hamsters. As CLA was shown to induce proliferation of peroxisomes in the liver of mice (Belury et al. 1997), the liver was investigated microscopically and palmitoyl CoA oxidase (EC 1.3.3.6) and carnitine acetyl transferase (EC 2.3.1.7) activities were determined as a measure of peroxisome proliferation. 
Table 1. Composition ( $\mathrm{g} / 100 \mathrm{~g}$ total fatty acids) of the fats present in the experimental diets* $^{*}$

\begin{tabular}{|c|c|c|c|c|}
\hline \multirow[b]{2}{*}{ Fatty acid $†$} & \multicolumn{4}{|c|}{ Group } \\
\hline & Control & CLA mix & c9,t11 CLA & $\mathrm{t} 10, \mathrm{c} 12 \mathrm{CLA}$ \\
\hline $14: 0$ & 0.9 & 0.9 & 0.9 & 0.8 \\
\hline $16: 0$ & 33.4 & 33.8 & 34.0 & 33.6 \\
\hline 18:0 & 4.4 & 4.2 & $4 \cdot 1$ & 4.4 \\
\hline $18: 1$ & $36 \cdot 1$ & $36 \cdot 1$ & $36 \cdot 2$ & $36 \cdot 1$ \\
\hline $18: 2 n-6$ & $23 \cdot 0$ & $18 \cdot 2$ & $18 \cdot 2$ & $18 \cdot 2$ \\
\hline c9,t11 CLA & - & 2.43 & 4.53 & 0.48 \\
\hline $\mathrm{t} 10, \mathrm{c} 12 \mathrm{CLA}$ & - & 2.44 & 0.32 & 3.95 \\
\hline Other CLA isomers $\ddagger$ & - & 0.27 & 0.21 & 0.72 \\
\hline $18: 3$ & 0.4 & 0.3 & 0.3 & 0.3 \\
\hline $20: 0$ & 0.4 & 0.3 & 0.3 & 0.4 \\
\hline $22: 0$ & 0.3 & 0.2 & 0.2 & 0.2 \\
\hline
\end{tabular}

CLA, conjugated linoleic acid; c, cis; $t$, trans.

* The diets contained $131 \mathrm{~g}$ fat $/ \mathrm{kg}$ (30\% energy). The fats used in the preparation of the diets were: palm oil (Chempri BV, Raamsdonkveer, The Netherlands), sunflowerseed oil (Chempri BV), higholeic-acid sunflowerseed oil (Contined BV, Bennekom, The Netherlands), CLA-rich glyceride preparations.

† Main fatty acids ( $>0.2 \mathrm{~g} / 100 \mathrm{~g}$ total fatty acids) only.

$\ddagger$ Sum of $t 8, c 10, c 9, c 11, t 9, t 11, c 10, c 12, t 10, t 12$ and $c 11, t 13$ CLA isomers.

\section{Materials and methods \\ Preparation of glycerides containing conjugated linoleic acid isomers}

CLA isomers were synthesized according to a modification of the method of Ip et al. (1991). Safflower oil (70 g linoleic $\mathrm{acid} / 100 \mathrm{~g}$ ) was hydrolysed and the linoleic acid isomerized to a mixture of conjugated $\mathrm{C}_{18}$ diene isomers with a solution of $\mathrm{NaOH}$ in monopropylene glycol at $155^{\circ}$ under a $\mathrm{N}_{2}$ atmosphere for $3 \mathrm{~h}$. After acidification the oil phase was separated from the water phase. Next, the oil was washed, dried, filtered and stored at $-25^{\circ}$. Approximately $90 \%$ of the linoleic acid was converted into CLA isomers which consisted mainly of c9,t11 CLA and t10,c12 CLA in equal amounts (CLA free fatty acid isomers mixture).

To prepare enriched c9,t11 CLA and t10,c12 CLA preparations the c9,t11 CLA isomer in the CLA free fatty acid isomers mixture was selectively esterified with lauryl alcohol using a lipase from Geotrichum candidum (Amano Pharmaceutical, Nagoya, Japan). The lauryl esters enriched in c9,t11 CLA were separated from free t10,c12 CLA by molecular distillation and the esters hydrolysed to free fatty acids. Both free fatty acid preparations were further purified using conventional methods. In order to incorporate the CLA isomers into TAG, three parts of either the CLA isomers mixture, the c9,t11 CLA isomer or the t10,c12 CLA isomer were mixed with ten parts of palm oil. The CLA isomers were interesterified by adding $5 \%$ immobilized Rhizomucor miehei lipase (Lipozyme-IM, Novo Nordisk, Bagsvaerd, Denmark) followed by gentle stirring for $44 \mathrm{~h}$ at $60^{\circ}$. The reaction mixtures were filtered to remove the immobilized lipase and the free fatty acids were removed by washing with aqueous methanol. The CLArich glyceride preparations thus obtained were refined using conventional methods and used to prepare the fat blends of the foods (Table 1). Partial glyceride content was determined by silica-gel HPLC with 12-hydroxy octadecanol as internal standard. The CLA isomers mixture, c9,t11 CLA isomer, and t10,c12 CLA isomer preparations contained
910, 910, and $760 \mathrm{~g} \mathrm{TAG} / \mathrm{kg}$, respectively, and 70, 80 and $200 \mathrm{~g}$ diacylglycerols $/ \mathrm{kg}$ respectively. Monoacylglycerols and free fatty acids were both approximately $10 \mathrm{~g} / \mathrm{kg}$.

\section{Animals and diets}

The experimental protocol was approved by the Animal Experiments Committee of Unilever Research Vlaardingen. Male $\mathrm{F}_{1} \mathrm{~B}$ hybrid hamsters (Bio Breeders Inc., Fitchbury, MA, USA; aged 11 weeks at arrival) were used. They were individually housed in plastic cages $(210 \times 160 \times 140 \mathrm{~mm})$ with sawdust as bedding (except in the weeks in which food consumption was measured) and placed in an airconditioned room $\left(22-25^{\circ}\right.$; relative humidity approximately $55 \%$ ) with a fixed day-night rhythm (light on from 07.00 to 19.00 hours). The hamsters were fed on purified diets as described previously (De Deckere et al. 1993). In the present experiment, however, the amount of fat was $131 \mathrm{~g} / \mathrm{kg}$ (30\% energy), the amount of starch $557 \mathrm{~g} / \mathrm{kg}$ and the amount of cholesterol $0 \cdot 1 \mathrm{~g} / \mathrm{kg}$. After arrival the hamsters were acclimatized and fed on the control diet without CLA (Table 1) for 2 weeks, after which they were allocated to four groups of thirty-two animals each (randomized design) with similar mean body weights and fed on diets containing no CLA (control), a mixture of c9,t11 and t10,c12 CLA (CLA mix; $3 \mathrm{~g}$ c9,t11 CLA/kg; $3 \mathrm{~g} \mathrm{t10,c12} \mathrm{CLA/kg),} \mathrm{the}$ c9,t11 CLA isomer (c9,t11 CLA; 5.6 g c9,t11 CLA/kg; $0.4 \mathrm{~g}$ $\mathrm{t} 10, \mathrm{c} 12 \mathrm{CLA} / \mathrm{kg})$, and the $\mathrm{t} 10, \mathrm{c} 12$ CLA isomer (t10,c12 CLA; $0.6 \mathrm{~g} \mathrm{c9,t11} \mathrm{CLA/kg;} 4.9 \mathrm{~g} \mathrm{t10,c12} \mathrm{CLA/kg).} \mathrm{The}$ diets were fed for 8 weeks (weeks 1-8). The animals had free access to food and water, but before blood collection they were fasted for $16 \mathrm{~h}$. Blood samples were collected under inhalation anaesthesia (halothane- $-\mathrm{O}_{2}-\mathrm{N}_{2} \mathrm{O}$ ) by retroorbital puncture in the beginning of weeks $5(\mathrm{t}=4$ weeks) and $9(\mathrm{t}=8$ weeks $)$. EDTA-treated plasma was prepared and stored at $-80^{\circ}$. Food intake was determined in weeks 3 and 8 over $4 \mathrm{~d}$. Body weights were measured and clinical observations made once weekly.

In week 9 following blood collection, eight animals per 
group were killed on four consecutive days. Autopsy was carried out on all animals. Liver, epididymal fat pads, and kidneys were removed and weighed. One half of the median lobe of the liver (for histometry) was stored in formaldehyde $(40 \mathrm{ml} / \mathrm{l})$. Samples of the liver were also stored at $-80^{\circ}$ and epididymal fat pads at $-20^{\circ}$.

\section{Liver histometry and histopathology}

As a measure of liver hypertrophy and hyperplasia the number of cell nuclei $/ \mathrm{mm}^{2}$ was determined in $3.5 \mu \mathrm{m}$ thick sections of embedded liver tissue stained with haematoxylin-azophloxin. Five microscopic fields per liver were counted using a Kontron/Zeiss interactive image analysis system (Carl Zeiss, Weesp, The Netherlands). Cryostat liver slides prepared from frozen samples were stained for catalase (EC 1.11.1.6) as described by Novikoff et al. (1972) and the amount of stain was scored independently by two experienced microscopists.

\section{Cholesterol and triacylglycerol concentrations}

Total cholesterol (TC) in plasma was measured using a commercial test combination (CHOD-PAP, C-system, Boehringer, Mannheim, Germany). Total and free glycerol levels in plasma were determined enzymically (GPO-PAP method, Roche Diagnostics, Basel, Switzerland and GPOTrinder method, Sigma Chemical Co., St Louis, MO, USA). Plasma total TAG concentration was calculated as the difference between the total and free glycerol concentrations. Cholesterol and TAG of the VLDL, LDL and HDL fractions were determined as for plasma, except that for the VLDL and LDL fractions free glycerol was not determined and TAG was equalized to total glycerol. Liver cholesterol and TAG were determined in liver lipid extracts (see later) in a similar way to plasma TC and TAG.

\section{Separation of plasma lipoproteins}

Separation of plasma lipoproteins was done by sequential micro-ultracentrifugation (Beckman Optima TLX ultracentrifuge (Beckman, Palo Alto, CA, USA), 120000 rev./min, $\left.10^{\circ}\right)$. Plasma $(500 \mu \mathrm{l})$ was transferred to a thick-walled polycarbonate tube $(11 \times 35 \mathrm{~mm}$, Beckman), overlaid with $500 \mu l 1.006 \mathrm{~g} / \mathrm{ml} \mathrm{NaCl}$ solution and ultracentrifuged for $30 \mathrm{~min}$. The upper layer (VLDL fraction) was harvested by slicing the tube at $9 \mathrm{~mm}$ and collecting the supernatant fraction (range 350-390 $\mu$ l; Beckman Centri Tube Slicer). The density of the lower fraction (range 610-650 $\mu \mathrm{l}$ ) was adjusted to $1.063 \mathrm{~g} / \mathrm{ml}$ with $52 \mathrm{mg} \mathrm{KBr}$, overlaid with $500 \mu \mathrm{l}$ $1.044 \mathrm{~g} / \mathrm{ml} \mathrm{NaCl}$ solution and ultracentrifuged for $60 \mathrm{~min}$. The upper layer (480-520 $\mu \mathrm{l}$; LDL fraction) was harvested in a similar way to VLDL. The lower fraction $(610-650 \mu \mathrm{l})$ was collected as HDL + other components (mainly HDL fraction). The fractions were stored at $-20^{\circ}$. The amounts of VLDL, LDL and HDL were calculated on the basis of the initial plasma volume and the volumes of the various fractions.

\section{Fatty acid analyses}

Homogenates (Ultra Turrax, Janke \& Kunkel, Staufen,
Germany) of liver and fat-pad samples and plasma LDL and VLDL fractions were extracted with dichloromethanemethanol (2:1, v/v; Folch et al. 1957; Hamilton \& Hamilton, 1992). The organic phase (lipid extract) was washed with $3 \mathrm{M}-\mathrm{NaCl}$. Lipid extracts were separated into PL and TAG fractions by means of solid-phase extraction according to polarity by using Sep-Pak silica cartridges (Waters, Milford, MA, USA). The amount of sample was 10$50 \mathrm{mg}$ per solid-phase extraction column. Successively, cholesterol esters were eluted with $8 \mathrm{ml}$ heptane-diethyl ether $(100: 1 \cdot 5, \mathrm{v} / \mathrm{v})$, TAG eluted with $5 \mathrm{ml}$ heptane-diethyl ether $(90: 10, \mathrm{v} / \mathrm{v})$, and PL eluted with $4 \mathrm{ml}$ methanoldichloromethane-water (10:5:4, by vol.). To the PL fraction $1 \mathrm{ml}$ water and $3 \mathrm{ml}$ dichloromethane were added and the organic layer containing the PL was divided into two fractions for analysis of total PL fatty acids and $s n-2$ position fatty acids. All solvents were of reagent grade. The efficiency of the solid-phase extraction separation was checked by TLC (kieselgel 60 F254 plates, Merck, Darmstadt, Germany) with heptane-diethyl ether-acetic acid $(70: 30: 0 \cdot 5$, by vol.) as eluent.

$S n-2$ position fatty acids were obtained according a slightly modified procedure of Thompson \& Smith (1985). To dried PL fractions $1 \mathrm{ml}$ distilled diethyl ether $+1 \mathrm{ml}$ $0 \cdot 1 \mathrm{M}$-TRIS-buffer $\left(10 \mathrm{mM}-\mathrm{Ca}^{2+}, \mathrm{pH} 8 \cdot 1\right)$ and $15 \mu \mathrm{l}$ phospholipase $\mathrm{A}_{2}$ (EC 3.1.1.4) enzyme solution (1.8 units; Sigma) were added successively. After $1 \mathrm{~h}$ the reaction (room temperature, vigorously mixing) was stopped by adding an aqueous acetic acid solution $(100 \mathrm{ml} / \mathrm{l})$.

Fatty acid methyl esters (FAME) were prepared according to the method of Morrison \& Smith (1964) and Kramer (1997). BCR 162 control samples (Brunschwig, Amsterdam, The Netherlands) were used to check methylation. Evaporation of the solvent of the various fractions, hydrolysis of TAG and PL (0.5 M-NaOH-methanol, $70^{\circ}$, $30 \mathrm{~min})$, and methylation of the fatty acids $\left(\mathrm{BF}_{3}\right.$ in methanol, $200 \mathrm{ml} / \mathrm{l}$; Merck; room temperature, $1 \mathrm{~h}$ ) took place in $5 \mathrm{ml}$ reaction vials (Supelco, Bellefonte, PA, USA). FAME were extracted with heptane and washed with $3 \mathrm{M}-\mathrm{NaCl}$. The heptane layer was used for analysing FAME by highresolution GC (MEGA 2 series, Carlo Erba Instruments, Rodano, Italy) by using a CP-Sil 88 WCOT fused silica column $(50 \mathrm{~m} \times 0.25 \mathrm{~mm}$ i.d. $\times 0.20 \mu \mathrm{m}$ film thickness; Chrompack, Middelburg, The Netherlands). An isothermal system was used at $176^{\circ}$, total run time was $90 \mathrm{~min}$. The carrier gas was $\mathrm{He}$ and a flame-ionization detector was used for detection of FAME. The FAME retention times were checked with the GLC Reference Standard 87 from Nu-Check-Prep, Inc (Elysian, MN, USA). The peaks were integrated and reported using the Turbochrom data processing system of Perkin Elmer (Gouda, The Netherlands).

After addition of internal standard, plasma free fatty acids were isolated from plasma dichloromethane-methanol $(1: 1, \mathrm{v} / \mathrm{v})$ extracts by means of solid-phase extraction according to polarity (Sep-Pak silica cartridges). Free fatty acids were isolated from the appropriate fraction by using Florisil columns (Merck; ether-acetic acid (100:0.5, v/v) eluant following ether elution). FAME were prepared and fatty acids quantified by $\mathrm{GC}$ as described earlier.

Fatty acids of CLA preparations and of CLA-containing 
Table 2. Body weight, growth, average food intake, and organ weights of hamsters fed on a control diet or diets containing different isomers of conjugated linoleic acid (CLA) for 8 weeks*

(Mean values with their standard errors for thirty-two hamsters)

\begin{tabular}{|c|c|c|c|c|c|c|c|c|c|c|c|c|c|c|}
\hline \multirow[b]{2}{*}{ Diet } & \multicolumn{6}{|c|}{ Body weight (g) } & \multicolumn{2}{|c|}{ Growth $(\mathrm{g})$} & \multicolumn{2}{|c|}{ Liver (g) } & \multicolumn{2}{|c|}{$\begin{array}{l}\text { Epididymal } \\
\text { fat pads (g) }\end{array}$} & \multicolumn{2}{|c|}{ Kidneys (g) } \\
\hline & Mean & $\overline{\mathrm{SEM}}$ & Mean & $\overline{\text { SEM }}$ & Mean & $\overline{\text { SEM }}$ & Mean & $\overline{\text { SEM }}$ & Mean & $\overline{\text { SEM }}$ & Mean & $\overline{\text { SEM }}$ & Mean & SEM \\
\hline Control & $6 \cdot 2^{a}$ & 0.06 & 105 & 1.3 & $119^{a b}$ & 1.3 & $13 \cdot 4^{\mathrm{ab}}$ & 1.0 & $3 \cdot 15^{c}$ & 0.070 & $2 \cdot 16^{a}$ & 0.075 & $0.86^{a}$ & 0.015 \\
\hline CLA mix & $5 \cdot 8^{b}$ & 0.09 & 104 & 1.3 & $117^{a b}$ & 1.5 & $12 \cdot 3^{b}$ & 1.0 & $3.96^{\mathrm{a}}$ & 0.117 & $1.97^{b}$ & 0.054 & $0.91^{b}$ & 0.017 \\
\hline cis- 9 , trans -11 CLA & $6 \cdot 2^{\mathrm{a}}$ & 0.09 & 105 & 1.3 & $121^{\mathrm{a}}$ & 1.3 & $16 \cdot 2^{\mathrm{a}}$ & 0.9 & $3.39^{b}$ & 0.072 & $2 \cdot 25^{\mathrm{a}}$ & 0.087 & $0.87^{a}$ & 0.011 \\
\hline
\end{tabular}

$\overline{a, b, c}$ Mean values within a column not sharing a common superscript letter were significantly different (Student-Neuman-Keuls test; $P<0 \cdot 05)$.

${ }^{*}$ For details of diets, see Table 1 and pp. 310-311.

$\dagger$ Mean of two determinations over $4 \mathrm{~d}$.

glycerides were analysed by high-resolution GC. Glyceride samples $(10-20 \mathrm{mg})$ were hydrolysed in $2 \mathrm{ml} 0.5 \mathrm{M}-\mathrm{NaOH}-$ methanol for $5 \mathrm{~min}$ at $70^{\circ}$ and then cooled. To hydrolysed samples and to $10-20 \mathrm{mg}$ free fatty acid/fatty acid soap samples (CLA preparations) $2 \mathrm{ml} \mathrm{BF}_{3}$ in methanol $(140 \mathrm{ml} / \mathrm{l})$ was added and heated at $70^{\circ}$ for $1-2 \mathrm{~min}$ and $5 \mathrm{~min}$ respectively. After cooling, $2 \mathrm{ml}$ isooctane and $5 \mathrm{ml}$ water were added. The upper isooctane layer was removed, dried over anhydrous $\mathrm{Na}_{2} \mathrm{SO}_{4}$, and the concentration adjusted for analysis of the FAME as described earlier. The column oven was held at $120^{\circ}$ for $1 \mathrm{~min}$, then ramped to $160^{\circ}$ at $20^{\circ}$ per min, $160^{\circ}-180^{\circ}$ at $0 \cdot 5^{\circ}$ per min, and finally $180^{\circ}-230^{\circ}$ at $3^{\circ}$ per min. A Perkin Elmer 8420 GC system fitted with programmable temperature vaporizing injection in split injection mode and an AS8300 autosampler were used. The injector was held at $50^{\circ}$ for $0.1 \mathrm{~min}$ during injection, then ramped to $260^{\circ}$ for $3.5 \mathrm{~min}$ for transfer of the sample into the column oven zone. Samples $(0.5 \mu \mathrm{l})$ with a concentration of $10-25 \mathrm{mg} / \mathrm{ml}$ were used with split ratios adjusted for optimum column loading. Flameionization detector temperature was set at $260^{\circ}$ and total run time was $60 \mathrm{~min}$.

\section{Cyanide-insensitive palmitoyl CoA oxidase and carnitine acetyl transferase}

Frozen liver samples were thawed on ice, placed in $2 \mathrm{ml}$ 0.25 M-sucrose (Sherman Chemicals, Sandy, Beds., UK) per gram of liver, scissor-chopped, and homogenized using a Citenco homogenizer (Citenco, Borhamwood, Herts., UK). Homogenates were stored at $-70^{\circ}$. They were assayed for total protein by the bicinchoninic acid protein assay (Pierce, Rockford, IL, USA; Smith et al. 1985). Homogenates were diluted 1 in 200 with ultra pure water and assayed in triplicate against a protein standard (bovine serum albumin, Sigma) at $562 \mathrm{~nm}$ using a Shimadzu MPS 2000 spectrophotometer (Shimadzu, Milton Keynes, Bucks., UK).

For cyanide-insensitive palmitoyl CoA oxidase assay homogenates were diluted 1 in 10 with $0.154 \mathrm{M}-\mathrm{KCl}$ in

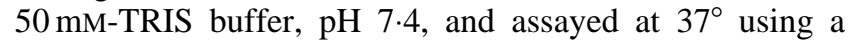
Shimadzu MPS 2000 spectrophotometer at $340 \mathrm{~nm}$ (Gray et al. 1982; all chemicals from Sigma). Sample and reference cuvettes contained $100 \mu \mathrm{l}$ cofactor solution $(2.5 \mathrm{mM}-$ NAD, 1.25 mM-coenzyme A, 62.5 mM-DL-dithiothreitol, $1.5 \mathrm{mg} \mathrm{BSA} / \mathrm{ml}), 100 \mu \mathrm{l} 15 \mathrm{mM}-\mathrm{KCN}, 10 \mu \mathrm{l}$ Triton-X 100
$(10 \mathrm{ml} / \mathrm{l}), 10 \mu \mathrm{l} 1.0 \mathrm{mM}-\mathrm{FAD}$ and $50 \mu \mathrm{l}$ homogenate made up to $0.95 \mathrm{ml}$ and $1.0 \mathrm{ml}$ respectively, with $50 \mathrm{mM}$-TRIS buffer, $\mathrm{pH}$ 7.6. The reaction was started by the addition of $50 \mu 10 \mathrm{mM}$-palmitoyl coenzyme A to the sample cuvette only.

For carnitine acetyl transferase assay homogenates were freeze-thawed four times, diluted 1 in 10 with $0.154 \mathrm{M}-\mathrm{KCl}$ in $50 \mathrm{mM}$-TRIS buffer, $\mathrm{pH} 7 \cdot 4$, and assayed at $37^{\circ}$ using a Shimadzu MPS 2000 spectrophotometer at $412 \mathrm{~nm}$ (Gray et al. 1982; all chemicals from Sigma). Sample and reference cuvettes contained $100 \mu 12.5 \mathrm{mM}$-acetyl coenzyme A, $100 \mu \mathrm{l} 1.56 \mathrm{mM}-5,5$-dithiobis (2-nitrobenzoic acid), and $50 \mu \mathrm{l}$ diluted homogenate made up to $0.9 \mathrm{ml}$ and $1.0 \mathrm{ml}$ respectively, with $25 \mathrm{mM}$-EDTA in $50 \mathrm{mM}$-TRIS buffer, $\mathrm{pH}$ 8.0 . The reaction was started by the addition of $100 \mu \mathrm{l}$ $31.25 \mathrm{mM}$-DL-carnitine to the sample cuvette only.

In both assays the increase with time in absorbance (at 340 and $412 \mathrm{~nm}$ ) was recorded, quantified as $\mathrm{nmol} / \mathrm{min}$ per $\mathrm{ml}$ diluted homogenate, then converted to $\mathrm{nmol} / \mathrm{min}$ per $\mathrm{mg}$ protein in the undiluted homogenates.

\section{Statistical analyses}

Results are presented as means with their standard errors. Statistical analysis was performed using the Statistical Analysis Systems program (version 6.12, 1996; SAS Institute Inc., Cary, NC, USA). Data were analysed by one-way ANOVA. Differences between the groups were established using the Student-Newman-Keuls multiple-range test. Significance was assessed at the $P<0.05$ level. Some of the fatty acids had groups with unequal variance and were therefore analysed by means of ANOVA on the ranks. Free fatty acids were analysed by means of Student's $t$ test.

\section{Results}

\section{Body weight, food intake, and organ weights}

The average food intakes of the CLA mix and c9,t11 CLA groups were similar and lower than the food intakes of the other two groups (Table 2). The mean growth values for the three CLA groups were not different from the mean growth value of the control group, but hamsters fed on the diets with the t10,c12 CLA isomer showed a smaller weight increase than hamsters fed on the diet with the c9,t11 CLA isomer. Correction of the mean growth values for the differences in 
food intake (covariable) hardly changed the values and the significant difference between the c9,t11 CLA and t10,c12 CLA groups remained present. Mean absolute and relative ( $\mathrm{g} / 100 \mathrm{~g}$ body weight; results not shown) weights of liver and kidneys of the CLA mix and t10,c12 CLA groups were similar, and higher than those of the control and c9,t11 CLA groups, whereas mean epididymal fat pads weights were lower.

\section{Plasma and liver lipids}

After 4 weeks of feeding $(\mathrm{t}=4$ weeks) plasma TC was lower in the CLA mix and t10,c12 CLA groups than in the other two groups (Table 3). After 8 weeks of feeding $(\mathrm{t}=8$ weeks), however, the differences in plasma TC were less, but the difference in plasma TC between the c9,t11 CLA group and the t10,c12 CLA group was still significant.

VLDL-cholesterol level was higher and LDL- and HDLcholesterol levels were lower in the CLA mix and t10,c12 CLA groups than in the control and c9,t11 CLA groups (Table 3). LDL-cholesterol was not correlated with liver weight and correction of the LDL-cholesterol values for the differences in liver weight between the groups did not affect the mean LDL-cholesterol values (results not shown).

Plasma total TAG concentration was higher in the CLA mix and t10,c12 CLA groups than in the other two groups (Table 3). All values were higher at $\mathrm{t}=8$ weeks than at $\mathrm{t}=4$ weeks. VLDL-, LDL- and HDL-TAG were higher in the CLA mix and t10,c12 CLA groups than in the control and c9,t11 CLA groups (Table 3). VLDL-TAG was positively correlated with liver weight and when VLDL-TAG was corrected for the differences in liver weight (covariable) then no significant differences in VLDL-TAG between the groups were present (range 1.03 (SE 0.09) to 1.20 (SE 0.09) $\mathrm{mmol} / \mathrm{l}$ ).

The liver free cholesterol, TC and TAG values of the four groups did not differ significantly (ranges 7·0-8.2, 7·6-9.6, and $4.9-5.6 \mu \mathrm{mol} / \mathrm{g}$ wet weight of liver respectively), but the values for the CLA mix and t10,c12 CLA groups were somewhat lower than for the other two groups. Expressed per total liver, the values differed even less and the TC and TAG values ranged between 27.2 and $32.9 \mu \mathrm{mol}$ and 17.5 and $19.4 \mu \mathrm{mol}$ respectively.

Plasma total free fatty acids were determined in the control and CLA mix groups only and were lower in the control group $(1.38$ (SE $0 \cdot 165) \mathrm{mmol} / \mathrm{l} ; n 7$ pooled samples of two animals) than in the CLA mix group $(1.98(\mathrm{SE} 0 \cdot 207) \mathrm{mmol} / \mathrm{l} ; n 8$ pooled samples of two animals; $P=0 \cdot 05)$.

\section{Fatty acid compositions of liver, VLDL, LDL, and fat pad triacylglycerols and of liver phospholipids}

The diets contained similar amounts of total 18:2 fatty acids (linoleic acid + CLA isomers). Although not statistically significantly different for all lipid fractions, total 18:2 in the TAG and PL fractions analysed tended to be lower for the CLA mix group and the t10,c12 CLA group than for the control and the c9,t11 CLA groups (Table 4). This was partly due to a much lower incorporation of the $\mathrm{t} 10, \mathrm{c} 12$ isomer than of the $\mathrm{c} 9, \mathrm{t} 11$ isomer. Furthermore, 
Table 4. Fatty acid compositions ( $\mathrm{g} / 100 \mathrm{~g}$ total fatty acids) of liver, VLDL, LDL, and fat pad triacylglycerols (TAG) and liver phospholipids (PL) of hamsters fed on a control diet or diets containing different isomers of conjugated linoleic acid (CLA) for 8 weeks*

(Mean values and mean values with their standard errors for four hamsters (liver, fat pads) or for eight pooled samples of four hamsters $(\mathrm{VLDL}, \mathrm{LDL}))$

\begin{tabular}{|c|c|c|c|c|c|c|c|c|c|c|c|c|}
\hline \multirow[b]{3}{*}{ Dietary group } & \multicolumn{12}{|c|}{ Fatty acid $†$} \\
\hline & \multirow{2}{*}{$\frac{18: 1 n-9}{\text { Mean }}$} & \multicolumn{2}{|c|}{$18: 2 n-6$} & \multirow{2}{*}{$\begin{array}{c}\text { c9,t11 } \\
\text { CLA } \\
\text { Mean }\end{array}$} & \multirow{2}{*}{$\begin{array}{c}\mathrm{t} 10, \mathrm{c} 12 \\
\mathrm{CLA} \\
\text { Mean }\end{array}$} & \multicolumn{2}{|c|}{$18: 2$ total } & \multicolumn{2}{|c|}{$18: 3 n-3$} & \multirow{2}{*}{$\frac{20: 4 n-6}{\text { Mean }}$} & \multicolumn{2}{|c|}{$22: 6 n-3$} \\
\hline & & Mean & SEM & & & Mean & SEM & Mean & SEM & & Mean & SEM \\
\hline \multicolumn{13}{|l|}{ Liver TAG } \\
\hline Control & 35.5 & $18 \cdot 6^{a}$ & 0.72 & 0.09 & 0.02 & $18 \cdot 7^{a}$ & 0.72 & $0.19^{a}$ & 0.01 & $3 \cdot 1$ & & \\
\hline CLA mix & 35.9 & $16 \cdot 1^{\mathrm{a}}$ & $1 \cdot 27$ & 0.88 & 0.30 & $17 \cdot 3^{a}$ & 0.33 & $0.11^{b}$ & 0.02 & $3 \cdot 2$ & & \\
\hline $\mathrm{c} 9, \mathrm{t} 11 \mathrm{CLA}$ & $35 \cdot 1$ & $17 \cdot 8^{a}$ & 0.79 & 1.74 & 0.06 & $19 \cdot 6^{a}$ & 0.91 & $0.19^{a}$ & 0.03 & 2.8 & & \\
\hline $\mathrm{t} 10, \mathrm{c} 12 \mathrm{CLA}$ & 38.0 & $15 \cdot 2^{a}$ & 0.50 & 0.27 & 0.44 & $15 \cdot 9^{a}$ & 0.52 & $0.09^{b}$ & 0.01 & 3.0 & & \\
\hline \multicolumn{13}{|l|}{ Liver PL, total } \\
\hline Control & $10 \cdot 5$ & $18 \cdot 1^{a}$ & 0.50 & 0.04 & 0.01 & $18 \cdot 1^{a}$ & 0.50 & & & $18 \cdot 6$ & $7 \cdot 4^{a}$ & 0.31 \\
\hline CLA mix & 11.4 & $16 \cdot 6^{\mathrm{bc}}$ & 0.14 & 0.25 & 0.13 & $17 \cdot 0^{\mathrm{ab}}$ & 0.15 & & & $17 \cdot 8$ & $5 \cdot 9^{b}$ & 0.12 \\
\hline $\mathrm{c} 9, \mathrm{t} 11 \mathrm{CLA}$ & 10.9 & $17 \cdot 4^{a b}$ & 0.35 & 0.42 & 0.02 & $17 \cdot 8^{a}$ & 0.36 & & & $18 \cdot 1$ & $7 \cdot 0^{a}$ & 0.20 \\
\hline $\mathrm{t} 10, \mathrm{c} 12 \mathrm{CLA}$ & $11 \cdot 2$ & $16 \cdot 2^{c}$ & $0 \cdot 21$ & 0.07 & 0.20 & $16 \cdot 5^{b}$ & 0.22 & & & 18.0 & $5 \cdot 9^{b}$ & 0.25 \\
\hline \multicolumn{13}{|l|}{ Liver PL, sn-2 } \\
\hline Control & $9 \cdot 2$ & $24 \cdot 7^{a}$ & 0.48 & 0.03 & 0.00 & $24 \cdot 7^{\mathrm{ab}}$ & 0.49 & & & 38.5 & $15 \cdot 3^{a}$ & 0.21 \\
\hline CLA mix & $12 \cdot 3$ & $23 \cdot 1^{a}$ & 0.32 & 0.35 & 0.10 & $23 \cdot 5^{b}$ & 0.33 & & & $36 \cdot 1$ & $11 \cdot 6^{c}$ & 0.27 \\
\hline c9,t11 CLA & $10 \cdot 4$ & $25 \cdot 5^{\mathrm{a}}$ & $1 \cdot 14$ & 0.67 & 0.01 & $26 \cdot 2^{a}$ & $1 \cdot 15$ & & & $36 \cdot 5$ & $13 \cdot 7^{b}$ & 0.16 \\
\hline $\mathrm{t} 10, \mathrm{c} 12 \mathrm{CLA}$ & $11 \cdot 7$ & $22 \cdot 8^{a}$ & 0.42 & 0.11 & 0.18 & $23 \cdot 1^{b}$ & 0.43 & & & $36 \cdot 3$ & $11 \cdot 4^{\mathrm{c}}$ & 0.76 \\
\hline \multicolumn{13}{|l|}{ VLDL-TAG } \\
\hline Control & $31 \cdot 7$ & $24 \cdot 3^{a}$ & 0.27 & 0.09 & 0.07 & $24 \cdot 5^{a}$ & 0.26 & $0.32^{a}$ & 0.01 & $3 \cdot 4$ & & \\
\hline CLA mix & $36 \cdot 1$ & $19 \cdot 7^{b}$ & 0.28 & 0.86 & 0.31 & $20 \cdot 9^{b}$ & 0.30 & $0.13^{c}$ & 0.02 & 2.9 & & \\
\hline $\mathrm{c} 9, \mathrm{t} 11 \mathrm{CLA}$ & $32 \cdot 8$ & $21.9^{c}$ & 0.17 & 1.67 & 0.10 & $23 \cdot 7^{a}$ & 0.17 & $0.27^{b}$ & 0.01 & $3 \cdot 3$ & & \\
\hline $\mathrm{t} 10, \mathrm{c} 12 \mathrm{CLA}$ & $36 \cdot 7$ & $19 \cdot 6^{b}$ & 0.30 & 0.28 & 0.49 & $20 \cdot 3^{b}$ & 0.33 & $0.13^{c}$ & 0.01 & 2.9 & & \\
\hline \multicolumn{13}{|l|}{ LDL-TAG } \\
\hline Control & $24 \cdot 8$ & $31 \cdot 2^{a}$ & 0.24 & 0.02 & 0.00 & $31 \cdot 2^{a}$ & 0.26 & $0.11^{a}$ & 0.02 & $8 \cdot 7$ & $1 \cdot 9^{a}$ & 0.14 \\
\hline CLA mix & 28.0 & $27 \cdot 2^{b}$ & 0.48 & 0.50 & 0.15 & $27 \cdot 9^{b}$ & 0.47 & $0.06^{a}$ & 0.02 & $8 \cdot 4$ & $1.6^{a b}$ & 0.05 \\
\hline$c 9, \mathrm{t} 11 \mathrm{CLA}$ & $25 \cdot 6$ & $30 \cdot 1^{a}$ & 0.27 & 1.00 & 0.01 & $31 \cdot 1^{a}$ & 0.26 & $0.07^{a}$ & 0.03 & $7 \cdot 3$ & $1 \cdot 6^{\mathrm{ab}}$ & 0.24 \\
\hline $\mathrm{t} 10, \mathrm{c} 12 \mathrm{CLA}$ & 28.4 & $27 \cdot 7^{b}$ & 0.60 & 0.11 & 0.20 & $28 \cdot 0^{b}$ & 0.61 & $0.04^{a}$ & 0.02 & $8 \cdot 3$ & $1 \cdot 3^{b}$ & 0.19 \\
\hline \multicolumn{13}{|l|}{ Fat pad TAG } \\
\hline Control & $44 \cdot 3$ & $16 \cdot 7^{\mathrm{a}}$ & 0.15 & 0.13 & 0.01 & $16 \cdot 8^{a}$ & 0.15 & $0.42^{a}$ & 0.03 & & & \\
\hline CLA mix & $46 \cdot 9$ & $13 \cdot 5^{b}$ & 0.59 & 1.05 & 0.47 & $15 \cdot 0^{a}$ & 0.65 & $0.18^{b}$ & 0.02 & & & \\
\hline $\mathrm{c} 9, \mathrm{t} 11 \mathrm{CLA}$ & 44.4 & $14 \cdot 8^{b}$ & 0.37 & $1 \cdot 78$ & 0.08 & $16 \cdot 7^{\mathrm{a}}$ & 0.43 & $0.35^{a}$ & 0.02 & & & \\
\hline $\mathrm{t} 10, \mathrm{c} 12 \mathrm{CLA}$ & 49.6 & $11 \cdot 8^{c}$ & 0.59 & 0.31 & 0.66 & $12 \cdot 7^{b}$ & 0.67 & $0.11^{b}$ & 0.02 & & & \\
\hline
\end{tabular}

c, cis; t, trans.

a,b,c Mean values within a column not sharing a common superscript letter were significantly different (Student-Neuman-Keuls test; $P<0.05)$.

${ }^{*}$ For details of diets and procedures, see Table 1 and pp. 310-312.

† Statistical analysis is only presented for 18:2n-6, 18:2 total, 18:3n-3, and 22:6n-3.

t10,c12 CLA, in comparison with c9,t11 CLA, led to a lower incorporation of linoleic acid in the lipid fractions and also to a lower incorporation of linolenic acid and 22:6n-3 (although not statistically significantly different for all fractions). No effect of CLA on the amount of arachidonic acid (20:4n-6) in the lipid fractions, except in VLDL-TAG, was found. In all lipid fractions oleic acid was higher in the CLA mix and the t10,c12 CLA groups than in the other two groups.

\section{Peroxisome proliferation}

As measures of peroxisome proliferation, palmitoyl CoA oxidase and carnitine acetyl transferase activities in liver homogenates were determined in eight hamsters of the control and CLA mix groups only. No appreciable differences between the two groups were found. Palmitoyl CoA oxidase activities in the control and CLA mix groups were $5.92(\mathrm{SE} 0.91)$ and $5.65(\mathrm{SE} 0.80) \mathrm{nmol} / \mathrm{min}$ per $\mathrm{mg}$ protein respectively and carnitine acetyl transferase activities were 15.34 (SE 3.03) and 13.87 (SE 2.32) nmol/min per mg pro- tein. Moreover, no differences between the four groups in the liver catalase concentrations were found (microscopic scoring, $n$ 16).

\section{Liver histometry and histopathology}

In sixteen animals of each group the number of hepatocellular cell nuclei per $\mathrm{mm}^{2}$ liver area was counted. The number of nuclei was significantly lower in the CLA groups than in the control group (2525 (SE 65)) and significantly lower in the t10,c12 CLA group (1909 (SE 86)), CLA mix (2064 (SE 62)) than in the c9,t11 CLA (2204 (SE 71)) group indicating liver hypertrophy induced by the t10,c12 CLA isomer. No differences between the four groups in microscopic picture (haematoxylin-azophloxin staining, $n$ 32) were found.

\section{Discussion}

This is the first reported study using individual isomers (c9,t11 and t10,c12) of CLA incorporated into glycerides. It 
Table 5. Summary of effects of cis-9, trans-11 conjugated linoleic acid (CLA), trans-10, cis-12 CLA and a mixture of CLA isomers relative to control (\%) together with the statistical evaluation of the measured values (statistics)

\begin{tabular}{|c|c|c|c|c|c|c|}
\hline \multirow[b]{3}{*}{ Variable } & \multicolumn{6}{|c|}{ Group } \\
\hline & \multicolumn{2}{|c|}{ c9,t11 CLA } & \multicolumn{2}{|c|}{$\mathrm{t} 10, \mathrm{c} 12 \mathrm{CLA}$} & \multicolumn{2}{|c|}{ CLA mixture } \\
\hline & $\%$ & Statistics & $\%$ & Statistics & $\%$ & Statistics \\
\hline \multicolumn{7}{|l|}{ Animal } \\
\hline Food intake & 0 & NS & -6 & S & -6 & S \\
\hline Growth* & +21 & NS & -19 & NS & -8 & NS \\
\hline \multicolumn{7}{|l|}{ Organ weights } \\
\hline Liver & +8 & S & +25 & S & +26 & $\mathrm{~S}$ \\
\hline Fat pads & +4 & NS & -16 & $\mathrm{~S}$ & -9 & $\mathrm{~S}$ \\
\hline Kidneys & +1 & NS & +7 & $\mathrm{~S}$ & +6 & $\mathrm{~S}$ \\
\hline \multicolumn{7}{|l|}{ Plasma } \\
\hline TC, 4 weeks & -1 & NS & -13 & S & -13 & S \\
\hline TC, 8 weeks & +2 & NS & -8 & NS & -4 & NS \\
\hline TAG, 4 weeks & +2 & NS & +53 & S & +38 & $\mathrm{~S}$ \\
\hline TAG, 8 weeks & +11 & NS & +52 & $\mathrm{~S}$ & +62 & $\mathrm{~S}$ \\
\hline \multicolumn{7}{|l|}{ Lipoproteins } \\
\hline VLDL-cholesterol & +20 & NS & +50 & S & +67 & S \\
\hline VLDL-TAG & +20 & NS & +61 & $\mathrm{~S}$ & +80 & $\mathrm{~S}$ \\
\hline LDL-cholesterol & +7 & NS & -18 & $\mathrm{~S}$ & -21 & $\mathrm{~S}$ \\
\hline HDL-cholesterol & 0 & NS & -11 & $\mathrm{~S}$ & -8 & $\mathrm{~S}$ \\
\hline \multicolumn{7}{|l|}{ Liver lipids } \\
\hline TC per $g$ & +13 & NS & -9 & NS & -10 & NS \\
\hline TC per liver & +21 & NS & +21 & NS & +13 & NS \\
\hline TAG per $g$ & -1 & NS & -10 & NS & -12 & NS \\
\hline TAG per liver & +6 & NS & +11 & NS & +10 & NS \\
\hline Liver cell nuclei† & -13 & S & -24 & $\mathrm{~S}$ & -18 & $S$ \\
\hline
\end{tabular}

c, cis; t, trans; S, significantly different from control; TC, total cholesterol; TAG, triacylglycerol.

${ }^{*}$ Note that growth was little in hamsters of this age.

† Per $\mathrm{mm}^{2}$ of liver area.

appears that c9,t11 CLA and t10,c12 CLA differ greatly in their effects. A third CLA group receiving a mixture of these two isomers (CLA mix) was also present in the study and the results for this group were similar to results obtained in a previous study on CLA mix (van Amelsvoort \& Meijer, 1997). The effects of the three CLA preparations with respect to the control group are summarized in Table 5. Generally, the diets containing CLA mix and t10,c12 CLA, in comparison with the control diet, affected the variables studied in a similar way, whereas the diet containing c9,t11 CLA affected the variables to a lesser extent, if at all. Only liver weight (Table 2) and the number of cell nuclei in liver sections, in addition to the fatty acid composition of some of the lipid fractions (Table 4), were affected by c9,t11 CLA. The c9,t11 CLA preparation, however, contained approximately $6 \%$ (of total CLA isomers) t10,c12 CLA and this contamination might have contributed to these effects. The results suggest that $t 10, c 12$ CLA is the active agent. The diet with the CLA mix contained $3 \mathrm{~g} \mathrm{t10,c12} \mathrm{CLA} / \mathrm{kg}(0.70 \%$ energy). This amount appears to be sufficient to evoke physiological effects. The CLA preparations also contained a number of other CLA isomers, but they were present in all three CLA preparations and the individual amounts were low.

Hamsters fed on a diet containing a small amount of cholesterol $(0 \cdot 1 \mathrm{~g} / \mathrm{kg})$ were used to investigate the effects of CLA on plasma cholesterol and other lipid variables, because the hamster is regarded as an appropiate animal model to investigate effects of fatty acids on lipoprotein cholesterol and other lipoprotein aspects. Like human sub- jects, the hamster has a significant amount of LDL and cholesteryl ester transferase activity in plasma, and cholesterol synthesis and the regulation of the LDL receptor are sensitive to dietary fatty acids. Furthermore, the rate of hepatic cholesterol synthesis is relatively low compared with that of the whole animal, and bile acid synthesis is not activated by dietary cholesterol (Spady \& Dietschy, 1983, 1985; Kris-Etherton \& Dietschy, 1997; Nicolosi, 1997). In addition, like human liver, the hamster liver synthesizes VLDL particles which contain only apolipoprotein B-100 (Arbeeny et al. 1992). The diets were prepared under tightly controlled conditions, CLA was exchanged for linoleic acid, and the diets were fed in a parallel design. On the basis of this design a meaningful conclusion may be reached (Kris-Etherton \& Dietschy, 1997). Plasma cholesterol concentrations were not determined at the start of the experiment, because blood collection in young animals disturbs growth, and due to our experience with this model and the large number of animals per group it was not considered necessary. Furthermore, in a previous study similar effects of the CLA mix on plasma TC and total TAG were found (van Amelsvoort \& Meijer, 1997).

Plasma TC and LDL-cholesterol levels of the CLA mix and t10,c12 CLA groups were lower than those of the control and c9,t11 CLA groups. Studies by Nicolosi et al. (1997) and Lee et al. (1994) also suggest that a mixture of CLA free fatty acid isomers can lower plasma TC and LDLcholesterol levels. However, the hamster model used by Nicolosi et al. (1997) had a very high value of plasma TC (about $16 \mathrm{mmol} / \mathrm{l}$ ) and a very low level of HDL-cholesterol 
(about $1.5 \mathrm{mmol} / \mathrm{l})$. Usually, plasma TC values in hamsters are $3-4 \mathrm{mmol} / \mathrm{l}$ of which $50-70 \%$ is HDL-cholesterol (de Deckere et al. 1993). In the study by Lee et al. (1994) control rabbits were fed on diets supplying about $1.2 \mathrm{~g}$ linoleic acid daily, whereas the CLA group received in addition $0.5 \mathrm{~g} \mathrm{CLA} / \mathrm{d}$. After 12 weeks of treatment fasting LDL-cholesterol (but not plasma TC) levels were significantly lower in the CLA group. However, by the addition of CLA total linoleic acid (cis, cis linoleic acid + CLA) was $33 \%$ higher in the CLA group than in the control group. In our present study CLA was exchanged for linoleic acid and the total amount of linoleic acid was kept constant.

Fasting plasma TAG levels were elevated in the CLA mix and t10,c12 CLA groups compared with the control and c9,t11 CLA groups. The differences in liver weight might explain this result, because the means of the VLDL-TAG values of the four groups when corrected for the differences in liver weight did not differ from each other. If a larger liver per se had been the only cause of the increased plasma TAG amount then it might be expected that the plasma free fatty acid concentration would have been lower, because plasma free fatty acids are the main source of fatty acids for liver TAG synthesis in this state $(16 \mathrm{~h}$ fast). However, an increased free fatty acid concentration was found in the CLA mix group, in comparison with the control group. Plasma TAG can also be increased by inhibition of lipoprotein lipase (EC 3.1.1.34) activity. Such an effect has been found in adipocytes where CLA, in comparison with linoleic acid, decreased lipoprotein lipase activity (Park et al. 1997). The possible role of lipoprotein lipase is supported by the observation that CLA mix and t10,c12 CLA decreased LDL- and HDL-cholesterol levels and increased LDL- and HDL-TAG levels. These effects have also been found in patients with no functional lipoprotein lipase (Pacy et al. 1993). Opposite effects have been found in hamsters. An increase in lipoprotein lipase activity increased plasma TC and HDL-cholesterol and decreased plasma TAG levels (Tsutsumi et al. 1997).

The effect on LDL-cholesterol can be regarded as beneficial with respect to cardiovascular diseases. The effect of t10,c12 CLA on LDL-cholesterol was not related to the effect of t10,c12 CLA on liver weight. No significant effects on plasma TAG values were found by Lee et al. (1994) and Nicolosi et al. (1997) showing that the effect of CLA on plasma TAG may depend on the animal model and experimental conditions used which makes extrapolation of the results for TAG to man questionable.

Another effect found was the higher liver weight in the CLA mix and t10,c12 CLA groups. This was not accompanied by a higher level of lipids in the liver as found in mice (Belury et al. 1997). An increase in liver weight (22\%) in mice in response to a mixture of CLA free fatty acids was also found by West et al. (1998). The authors suggested that this was due to lipid deposition, but lipid was not determined. Belury et al. (1997) have found that CLA may induce peroxisome proliferation in mice and consequently hypertrophy of the liver. We also found hypertrophy of the liver in response to $\mathrm{t} 10, \mathrm{c} 12 \mathrm{CLA}$, but no effect on markers of peroxisome proliferation such as palmitoyl CoA oxidase, carnitine acetyl transferase, and catalase, from which it can be concluded that peroxisome proliferation did not occur. In addition, in rodents and some other species peroxisome proliferation is accompanied by lower plasma VLDL-TAG levels and these levels were actually higher. Also in rats fed with 1.5 and $5 \%$ of energy as CLA no liver peroxisome proliferation or liver enlargement was found (Jones et al. 1999). The absence of an effect of CLA on peroxisome proliferation does not mean that oxidation of $\mathrm{t} 10, \mathrm{c} 12$ CLA in peroxisomes could not have been higher than that of c9,t11 CLA and might have led to a decrease in useful energy (ATP) production.

One of the striking results was the lower amount of the t10,c12 CLA isomer in the lipid fractions analysed. Generally, less than half the amount of that of c9,t11 CLA was present. This aspect was also found in the rat for adipose tissue, but not for total fatty acids of serum, liver and other organs (Sugano et al. 1997). Absorption of t10,c12 CLA might have been less than that of c9,t11 CLA, but this was not found in the rat for a mixture of CLA free fatty acid isomers given by oral administration (Sugano et al. 1997). We could not detect a decrease of t10,c12 CLA in the food due to oxidation (results not shown). The most likely explanation for the lower amount of t10,c12 CLA is a higher oxidation rate in vivo, in comparison with $\mathrm{c} 9, \mathrm{t} 11$ CLA. In addition to the lower amount of t10,c12 CLA, the amounts of linoleic and $\alpha$-linolenic acid in the TAG and liver PL were also reduced in the CLA mix and t10,c12 CLA groups, in comparison with the control and c9,t11 CLA groups. This is clearly shown by the differences in amounts of these polyunsaturated fatty acids between the c9,t11 CLA and $\mathrm{t} 10, \mathrm{c} 12$ CLA groups. This indicates that $\mathrm{t} 10, \mathrm{c} 12$ CLA stimulated the oxidation of $\mathrm{C}_{18}$ polyunsaturated fatty acids, whereas c9,t11 CLA did not. Also the study by West et al. (1998) suggests that a mixture of CLA isomers stimulates fatty acid oxidation. Interestingly, docosahexaenoic acid (22:6n-3; an elongation product of $\alpha$-linolenic acid) in the liver PL was decreased by t10,c12 CLA, but arachidonic acid (an elongation product of linoleic acid) was not. This could reflect the dietary supply of the precursor fatty acids (see Table 1).

In conclusion, t10,c12 CLA appeared to be the physiologically active CLA isomer and the natural isomer, c9,t11 CLA, present in dairy products and meat of ruminants had little or no effect on lipid metabolism in hamsters.

\section{Acknowledgements}

J. Benjamins, I. M. van Benschop, G. P. Dubbelman, S. Y. Gielen, E. van Haften, L. Kitchener, A. J. van der Kooij, J. N. J. J. Mathot, M. Meijers, R. Pendlington, C. Rawlins, E. Schuurbiers, W. G. Timmer, H. van Toor, J. van Toor, W. Tuitel, A. van Unnik, S. M. van der Veen, A. Wiersma and J. E. C. van Wijk are thanked for technical assistance, and M. Rudrum and L. B. M. Tijburg for critical reading of the manuscript.

\section{References}

Arbeeny CM, Meyers DS, Bergquist KE \& Gregg RE (1992) Inhibition of fatty acid synthesis decreases very low density lipoprotein secretion in the hamster. Journal of Lipid Research 33, 843-851. 
Banni S, Carta G, Contini MS, Angioni E, Deiana M, Dessi MA, Melis MP \& Corongiu FP (1995) Conjugated diene fatty acids in human and animal tissues. In Nutrition, Lipids, Health, and Disease, pp. 218-224 [ASH Ong, E Niki and L Packer, editors]. Champaign, IL: AOCS Press.

Banni S, Day BW, Evans RW, Corongiu FP \& Lombardi B (1994) Liquid chromatography-mass spectrometric analyses of conjugated diene fatty acids in a partially hydrogenated fat. Journal of the American Oil Chemists' Society 71, 1321-1325.

Belury MA, Moya-Camarena SY, Liu KL \& Vanden Heuvel JP (1997) Dietary conjugated linoleic acid induces peroxisomespecific enzyme accumulation and ornithine decarboxylase activity in mouse liver. Journal of Nutritional Biochemistry $\mathbf{8}$, 579-584.

Britton M, Fong C, Wickens D \& Yudkin J (1992) Diet as a source of phospholipid esterified 9,11-octadecadienoic acid in humans. Clinical Science 83, 97-101.

Chin SF, Liu W, Storkson JM, Ha YL \& Pariza MW (1992) Dietary sources of conjugated dienoic isomers of linoleic acid, a newly recognized class of anticarcinogens. Journal of Food Composition Analysis 5, 185-197.

de Deckere EAM, De Fouw NJ, Ritskes-Hoitinga J, Van Nielen WGL \& Blonk CG (1993) Effect of an atherogenic diet on lipoprotein cholesterol profile in the $\mathrm{F}_{1} \mathrm{~B}$ hybrid hamster. Atherosclerosis 103, 291-294.

Folch J, Lees M \& Sloane Stanley GH (1957) A simple method for the isolation and purification of total lipides from animal tissues. Journal of Biological Chemistry 226, 497-509.

Gray TJB, Beamand JA, Lake BG, Foster JR \& Gangolli SD (1982) Peroxisome proliferation in cultured rat hepatocytes produced by clofibrate and phthalate ester metabolites. Toxicology Letters 10, 273-279.

Hamilton RJ \& Hamilton S (1992) A Practical Approach: Lipid Analysis. New York, NY: Oxford University Press Inc.

Huang Y-C, Luedecke LO \& Shultz TD (1994) Effect of cheddar cheese consumption on plasma conjugated linoleic acid concentrations in men. Nutrition Research 14, 373-386.

Ip C, Scimeca JA \& Pariza MW (1991) Mammary cancer prevention by conjugated dienoic derivative of linoleic acid. Cancer Research 51, 6118-6124.

Ip C, Scimeca JA \& Thompson H (1995) Effect of timing and duration of dietary conjugated linoleic acid on mammary cancer prevention. Nutrition and Cancer 24, 241-247.

Jones PA, Lea LJ \& Pendlington RU (1999) Investigation of the potential of conjugated linoleic acid (CLA) to cause peroxisome proliferation in rats. Food and Chemical Toxicology (In the Press).

Kramer KG (1997) Evaluating acid base catalysts in the methylation of milk and rumen fatty acids with special emphasis on conjugated dienes and total trans fatty acids. Lipids 32, 12191228.

Kris-Etherton PM \& Dietschy J (1997) Design criteria for studies examining individual fatty acid effects on cardiovascular disease risk factors: human and animal studies. American Journal of Clinical Nutrition 65, Suppl., 1590S-1596S.

Lee KN, Kritchevsky D \& Pariza MW (1994) Conjugated linoleic acid and atherosclerosis in rabbits. Atherosclerosis 108, 19-25.

McGuire MK, Park Y, Behre RA, Harrison LY, Shultz TD \& McGuire MA (1997) Conjugated linoleic acid concentrations of human milk and infant formula. Nutrition Research 17, 12771283.

Morrison WR \& Smith LM (1964) Preparation of fatty acid methyl esters and dimethylacetals from lipids with boron fluoridemethanol. Journal of Lipid Research 5, 600-608.

Mossoba MM, McDonald R, Armstrong DJ \& Page SW (1991) Identification of minor $\mathrm{C}_{18}$ triene and conjugated diene isomers in hydrogenated oil and margarine by GC-MI-FT-IR spectroscopy. Journal of Chromatographic Science 29, 324-330.

Nicolosi RJ (1997) Dietary fat saturation effects on low-densitylipoprotein concentrations and metabolism in various animal models. American Journal of Clinical Nutrition 65, Suppl., $1617 \mathrm{~S}-1627 \mathrm{~S}$.

Nicolosi RJ, Rogers EJ, Kritchevsky D, Scimeca JA \& Huth PJ (1997) Dietary conjugated linoleic acid reduces plasma lipoproteins and early aortic atherosclerosis in hypercholesterolemic hamsters. Artery 22, 266-277.

Novikoff AB, Novikoff PM, Davis D \& Quintana N (1972) Studies on microperoxisomes II. Cytochemical method for light and electron microscopy. Journal of Histochemistry and Cytochemistry 20, 1006-1023.

Pacy PJH, Mitropoulos KA, Venkatesan S, Watts GF, Reeves BEA \& Halliday D (1993) Metabolism of apoprotein B-100 and of triglyceride-rich lipoprotein particles in the absence of functional lipoprotein lipase. Atherosclerosis 103, 231-243.

Pariza MW (1988) Dietary fat and cancer risk. Evidence and research needs. Annual Review of Nutrition 8, 167-183.

Park Y, Albright KJ, Liu W, Storkson JM, Cook ME \& Pariza MW (1997) Effect of conjugated linoleic acid on body composition in mice. Lipids 32, 853-858.

Smith PK, Krohn RI, Hermanson GT, Mallia AK \& Gartner FH (1985) Measurement of protein using bicinchoninic acid. Analytical Biochemistry 150, 76-85.

Spady DK \& Dietschy J (1983) Sterol synthesis in vivo in 18 tissues of the squirrel, monkey, guinea pig, rabbit, hamster, and rat. Journal of Lipid Research 24, 303-315.

Spady DK \& Dietschy J (1985) Dietary saturated triacylglycerols suppress hepatic low density lipoprotein receptor activity in the hamster. Proceedings of the National Academy of Sciences USA 82, 4526-4530.

Sugano M, Tsujita A, Yamasaki M, Yamada K, Ikeda I \& Kritchevsky D (1997) Lymphatic recovery, tissue distribution, and metabolic effects of conjugated linoleic acid in rats. Journal of Nutritional Biochemistry 8, 38-43.

Thompson S \& Smith M (1985) Measurement of the diene conjugated form of linoleic acid in plasma by high performance liquid chromatography: a questionable non-invasive assay of free radical activity? Chemical Biological Interactions 55, 357366.

Tsutsumi K, Inoue Y, Hagi A \& Murase T (1997) The novel compound NO-1886 elevates plasma high-density lipoprotein cholesterol levels in hamsters and rabbits by increasing lipoprotein lipase without any effect on cholesteryl ester transfer protein activity. Metabolism 46, 257-260.

van Amelsvoort JMM \& Meijer GW (1997) The effects of conjugated linoleic acid in dietary triglycerides on athersclerotic risk factors in the hamster. Atherosclerosis 134, 335 Abstr.

Visonneau S, Cesano A, Tepper SA, Scimeca JA, Santoli D \& Kritchevsky D (1997) Conjugated linoleic acid suppresses the growth of human breast adenocarcinoma cells in SCID mice. Anticancer Research 17, 969-974.

West DB, Delany JP, Camet PM, Blohm F, Truett AA \& Scimeca J (1998) Effects of conjugated linoleic acid on body fat and energy metabolism in the mouse. American Journal of Physiology 275, R667-R672. 